Annuaire suisse de politique de développement

25-2 | 2006

Paix et sécurité : les défis lancés à la coopération internationale

\title{
La Suisse et la construction de la paix en Colombie : le rôle clé de l'IUED
}

Jean-Pierre Gontard

\section{OpenEdition}

Journals

Édition électronique

URL : http://journals.openedition.org/aspd/275

DOI : 10.4000/aspd. 275

ISSN : 1663-9669

Éditeur

Institut de hautes études internationales et du développement

Édition imprimée

Date de publication : 1 octobre 2006

Pagination : 205-206

ISBN : 2-88247-064-9

ISSN : $1660-5934$

Référence électronique

Jean-Pierre Gontard, "La Suisse et la construction de la paix en Colombie : le rôle clé de l'IUED », Annuaire suisse de politique de développement [En ligne], 25-2 | 2006, mis en ligne le 25 janvier 2010, consulté le 08 septembre 2020. URL : http://journals.openedition.org/aspd/275; DOI : https://doi.org/ $10.4000 /$ aspd. 275 


\title{
La Suisse et la construction de la paix en Colombie: le rôle clé de l'IUED
}

\author{
Jean-Pierre Gontard*
}

L a Suisse, essentiellement par le biais de la Division politique IV "Sécurité humaine» du Département fédéral des affaires étrangères (DFAE), joue un rôle important de facilitateur dans le processus de paix en Colombie. L'échange d'un certain nombre de prisonniers entre le gouvernement et la principale guérilla du pays, les Forces armées révolutionnaires de Colombie (FARC), constitue un préalable aux négociations de paix. C'est dans ce contexte que depuis 1998, I'Institut universitaire d'études du développement (IUED) travaille à la négociation d'accords humanitaires, sur mandat de la Division politique Iv. Trois cent quatre militaires prisonniers ont déjà été libérés unilatéralement par les FARC ${ }^{1}$.

L'histoire de ce mandat remonte aux années 1970 et à l'intérêt manifesté alors par l'IUED pour la Colombie. Quelque 200 étudiants colombiens venant de régions et d'horizons très différents ont passé au moins deux ans au sein de I'Institut. Diverses études, évaluations ou thèses ont été entreprises sur ce pays, comme par exemple une évaluation du Service national d'apprentissage (SENA). En outre, I'IUED a collaboré avec plusieurs ONG colombiennes ou suisses impliquées dans des programmes de coopération, tel le Consejo regional indígena del Cauca (CRIC). II faut aussi mentionner la participation de l'Institut à l'élaboration de méthodes de planification et de budgétisation participatives dans certaines municipalités de l'est du pays, tout cela avec des anciens étudiants.

Que sont devenus ces étudiants colombiens? Certains ont intégré la diplomatie internationale, d'autres sont chercheurs ou enseignants. Un bon nombre s'est engagé dans la société civile colombienne, très dynamique. II en est qui se sont lancés dans la politique et certains, dont l'IUED n'avait pas de nouvelles, avaient changé d'identité pour entrer dans la clandestinité. Beaucoup des étudiants ont contribué aux travaux menés par I'Institut pour analyser non seulement le conflit colombien, mais aussi ses causes profondes. L'IUED leur a permis d'acquérir des outils méthodologiques... II ne leur restait plus qu'à rentrer chez eux et à s'en servir.

Par ailleurs, I'Institut a suivi attentivement les divers mouvements sociaux et les guérillas, de même que les nombreux efforts des gouvernements, tant libéraux que conservateurs, qui ont tous amorcé des négociations ces vingt dernières années.

II était naturel que de tels réseaux et de telles préoccupations génèrent des initiatives.

Ainsi, en 1998 déjà, l'IUED organise une première rencontre à Genève, intitulée "Les efforts de paix en Colombie et les ONG suisses", à laquelle participèrent, outre des ONG suisses et colombiennes, les partis politiques ainsi que les farC et l'Armée de libération nationale (eLN). Les deux organisations de la guérilla invitèrent ensuite un collaborateur de l'Iued à leur rendre visite. Un premier voyage permit un échange prospectif dans le cadre des contacts déjà établis entre le gouvernement colombien et ces deux mouvements armés. L'Institut fit en 1999 des propositions au Département fédéral des affaires étrangères pour s'impliquer dans le processus de paix. Une ligne

* Directeur adjoint chargé des projets spéciaux à I'Institut universitaire d'études du développement (IUED), Genève, et conseiller auprès du DFAE pour les processus de paix en Colombie.

1 Iván Márquez (membre du Secrétariat des FARC), El canje ;Ahora!, lettre datée du 28 août 2006, disponible sur la page <http://www.farcep.org/?node=2,2241,1\&highlight=el\%20canje\%20ahora> du site Internet des FARC. 
de communication s'établit entre le gouvernement colombien, les farc et I'ELN avec l'appui du gouvernement suisse. Le DFAE formalisa alors un mandat entre sa Division politique IV "Sécurité humaine" (DP IV) et l'IUED, pour lequel fut mis sur pied le "Bureau Colombie». Ce dernier est chargé, d'une part, d'effectuer une veille des informations utiles au mandat (revue de la presse, bulletins officiels, articles scientifiques colombiens, européens, américains, et de la littérature interne des mouvements de guérilla essentiellement) et, d'autre part, de participer aux négociations portant sur les conditions d'un nouvel échange de prisonniers civils et militaires entre les FARC et le gouvernement colombien.

Trois autres rencontres pour la paix en Colombie furent organisées par l'IUED sur mandat du gouvernement fédéral:

• en février 2000, "Problématique agraire. Un million et demi de déplacés par la violence", avec la participation des gouvernements suisse et colombien, des FarC, de l'ELn et de l'Armée populaire de libération (EPL);

$\square$ en juillet 2000, "Pour un consensus national pour la paix en Colombie", avec la participation des gouvernements de Colombie, de Cuba, d'Espagne, de France, de Norvège et de Suisse, de la société civile colombienne et de l'ELN;

- en février 2002, "L'avenir de la décentralisation: quinze ans d'expériences et perspectives ". Travaillèrent ensemble pendant une semaine, dans un hôtel genevois, le gouvernement colombien, les principaux partis et les représentants des trois guérillas, FARC, ELN et EPL.

L'IUED a publié les actes de cette dernière rencontre $^{2}$, qui a permis de traiter non seulement de la décentralisation mais de l'avenir politique, social et économique de la Colombie du point de vue des acteurs antagonistes. Quelques semaines plus tard, les processus de paix entre le gouvernement et les guérillas étaient interrompus mais les contacts ont été maintenus et l'Institut continue à s'efforcer de construire la confiance entre les Colombiens.

Ainsi, I'IUED travaille au service du DFAE à la recherche de conditions permettant la négociation d'accords humanitaires. Ceux-ci pourraient être suivis par des accords politiques sur les causes profondes du conflit contemporain le plus ancien d'Amérique latine.

2 J.-P. Gontard (dir.), El futuro de la descentralización: experiencias de quince años y perspectivas: Iv encuentro Colombia hacia la paz, Ginebra, Suiza, 7 al 9 de febrero del 2002, Ginebra, Instituto Universitario de Estudios del Desarollo (IUED): Bogotà, Fundación para la Participación Comunitaria (Parcomún), 2003. 